\title{
ENZYMATIC STUDIES ON THE MECHANISM OF ACTION OF CEFOXITIN \\ CORRELATION BETWEEN THE AFFINITIES OF CEFOXITIN TO PENICILLIN- BINDING PROTEINS AND ITS RATES OF INHIBITION OF THE RESPECTIVE PENICILLIN-SENSITIVE REACTIONS IN E. COLI
}

\author{
Michio Matsuhashi and Shigeo Tamaki \\ Institute of Applied Microbiology, University of Tokyo, \\ Bunkyo-ku, Tokyo, 113 Japan
}

(Received for publication July 18, 1978)

\begin{abstract}
The affinities of cefoxitin, a cephamycin antibiotic, to penicillin-binding proteins of Escherichia coli were reexamined using a recently developed method for separating penicillin-binding proteins. The inhibitions by this antibiotic of four measurable penicillin-sensitive enzymatic reactions, the reactions of D-alanine carboxypeptidases IA and IB, cross-bridge formation and concomitant release of D-alanine, were also measured. An approximate correlation was found between the affinities of cefoxitin to the penicillin-binding proteins responsible for these reactions and its rates of inhibition of the respective penicillin-sensitive reactions.
\end{abstract}

Cefoxitin (CFX) is a cephamycin antibiotic with a methoxy group at the $7 \alpha$-position of the cephalosporin skeleton ${ }^{1 \prime}$ and, like many other $\beta$-lactam antibiotics, it inhibits cell wall peptidoglycan synthesis, causing lysis of the cells. It is very resistant to $\beta$-lactamases. The binding affinities of cefoxitin to membrane proteins of Escherichia coli (penicillin-binding proteins, PBPs) have been investigated by SPRATT ${ }^{21}$ and its binding to PBPs of Proteus species ${ }^{31}$, and Pseudomonas aeruginosa ${ }^{41}$ have also been studied. Cefoxitin shows very high affinities to almost all the PBPs of the bacteria mentioned above, but it has low affinity to PBP-2, and also to PBP-4' of E. coli, to which mecillinam, an amidinopenicillin, binds exclusively. Information has recently been obtained on the functions of PBPs or their correspondence to known D-peptide-transferring enzymes, such as D-alanine carboxypeptidases, by isolating mutants lacking one of the PBPs. This paper describes the correlation between the high affinities of cefoxitin to each PBP in E. coli and its high potency to inhibit the respective enzyme reactions. This paper also reports new information on its binding affinities of cefoxitin to PBP-1A, $1 \mathrm{Bs}, 7$ and 8 . The separation of PBP-7 and 8 recently became possible by an improvement of the electrophoretic technique.

Similar work on another cephamycin antibiotic, CS-1170, has also been carried out and results will be reported elsewhere ${ }^{31}$.

\section{Materials and Methods}

Assay of Penicillin-binding Activities

A membrane preparation from E. coli K-12 strain JE1011 was used in penicillin-binding experiments. The procedures used in isolation of the membrane preparation and its binding of $\left[{ }^{14} \mathrm{C}\right]$ benzylpenicillin were described in detail previously ${ }^{2,5)}$. Experiments on the competition of cefoxitin with $\left[{ }^{14} \mathrm{C}\right]$ benzylpenicillin for binding the proteins were carried out in reaction mixtures containing in a final volume of $33 \mu \mathrm{l}: 600 \mu \mathrm{g}$ membrane fraction (as protein), $3 \mathrm{nmol}\left[{ }^{14} \mathrm{C}\right]$ benzylpenicillin, various amounts of cefoxitin or benzylpenicillin $\left(0.2 \sim 125 \mathrm{~mol}\right.$ equivalents to $\left[{ }^{14} \mathrm{C}\right]$ benzylpenicillin $)$ and $0.05 \mathrm{M}$ sodium

The following abbreviations are used: CFX, cefoxitin; MurNAc, N-acetylmuramic acid; m- $\mathrm{A}_{2} \mathrm{pm}$, mesodiaminopimelic acid; PBP, penicillin-binding protein. 
phosphate buffer, $\mathrm{pH}$ 7.0. Incubations were carried out at $30^{\circ} \mathrm{C}$ for 10 minutes and the binding proteins were separated by sodium dodecylsulfate-acrylamide slab-gel electrophoresis and estimated by fluorography as described previously ${ }^{2,5)}$. For a good separation of PBP-7 and 8, the slab gel was kept at $10^{\circ} \mathrm{C}$ during electrophoresis.

Preparation and Assay of Enzymes

For assays of D-alanine carboxypeptidases IA and IB, formation of cross-bridged peptidoglycan and simultaneous release of D-alanine, particulate membrane preparations were prepared from appropriate mutants of E. coli. D-Alanine carboxypeptidase IA activity was assayed with enzyme prepared from a dac $B$ strain $^{6}$, which is defective in D-alanine carboxypeptidase IB activity, while D-alanine carboxypeptidase IB activity was assayed with enzyme from a $\operatorname{dac} A \operatorname{strain}^{7)}$ which is defective in D-alanine carboxypeptidase IA activity. These activities were assayed by measuring release of $\mathrm{D}-\left[{ }^{14} \mathrm{C}\right]$ alanine from UDP-Nacetylmuramyl(MurNAc)-pentapeptide labeled in D- $\left[{ }^{14} \mathrm{C}\right] \mathrm{Ala}-\mathrm{D}-\left[{ }^{14} \mathrm{C}\right] \mathrm{Ala}(20 \mu \mathrm{Ci} / \mu \mathrm{mol})$. Release of Dalanine associated with formation of cross-bridged peptidoglycan was assayed using the enzyme from a double mutant dacA dacB strain. Substrate labeled at D- $\left[{ }^{14} \mathrm{C}\right] \mathrm{Ala}-\mathrm{D}-\left[{ }^{14} \mathrm{C}\right] \mathrm{Ala}(20 \mu \mathrm{Ci} / \mu \mathrm{mol})$ was used in assays involving release of $\mathrm{D}-\left[{ }^{14} \mathrm{C}\right] \mathrm{Ala}$ and substrate labeled at $\mathrm{m}-\left[{ }^{14} \mathrm{C}\right] \mathrm{A}_{2} \mathrm{pm}(82 \mu \mathrm{Ci} / \mu \mathrm{mol})$ was used for assay of formation of cross-linked peptidoglycan. The degree of crosslinking in the peptidoglycan labeled at $m-\left[{ }^{14} \mathrm{C}\right] \mathrm{A}_{2} \mathrm{pm}$ that was formed in the reaction was estimated as described previously $\mathrm{y}^{5,7)}$. All enzymatic reactions were carried out at $30^{\circ} \mathrm{C}$ for 1 hour.

Reagents

Cefoxitin was obtained from Daiichi Seiyaku Co., Tokyo; potassium benzylpenicillin was a commercial product of Takeda Chemical Industry Co., Osaka, Japan; $\left[{ }^{14} \mathrm{C}\right]$ benzylpenicillin (potassium 6phenyl-[1- $\left.{ }^{14} \mathrm{C}\right]$ acetamidopenicillanate, $\left.40 \sim 60 \mu \mathrm{Ci} / \mu \mathrm{mol}\right)$ was a product of the Radiochemical Centre, Ammersham, England. Sodium dodecylsulfate was purchased from Sigma Chemical Co., St. Louis, Mo., U.S.A. Sodium dodecyl-N-sarcosinate (Sarkosyl NL97, Ciba-Geigy) was provided from Kasho Co., Tokyo. Other chemicals used were standard commercial products. Radioactive substrates were prepared as described previously ${ }^{5,7)}$.

\section{Results and Discussion}

Affinities of Cefoxitin to Penicillin-binding Proteins (PBPs) in E. coli.

Under recently improved experimental conditions (see Materials and Methods) the PBPs in E. coli can be separated by sodium dodecylsulfate/acrylamide gel electrophoresis into nine major proteins, $1 \mathrm{~A}$ to 8 (Fig. 1). The affinities of cefoxitin to these PBPs were estimated in competition experiment by measuring the binding of $\left[{ }^{14} \mathrm{C}\right]$ benzylpenicillin to each PBP in the presence of increasing amounts of unlabeled cefoxitin. The fluorogram in Fig. 1 shows that cefoxitin has very high competitive ability with $\left[{ }^{14} \mathrm{C}\right]$ benzylpenicillin for binding to the low molecular PBPs $7 / 8,6,5,4$, and also the high molecular PBPs $1 \mathrm{~A}$ and $1 \mathrm{Bs}$. It shows lower competition for PBP-3 and no competition for PBP-2 or $4^{1}$.

PBP-1Bs are assumed to be identical with a peptidoglycan-cross-linking, enzyme, ${ }^{5)}$ and PBP$1 \mathrm{~A}$ (and/or 2) is thought to function in compensating for lack of PBP-1Bs as a "detour enzyme". 5) PBP-2 and 3 are supposed to be involved in the processes of sphere-rod conversion of cells $^{81}$ and of septum formation ${ }^{81}$, respectively. PBP-4 is 
identical with D-alanine carboxypeptidase $\mathrm{IB}^{6,9 !}$ and PBP-5 with D-alanine carboxypeptidase $\mathrm{IA}^{7,10)}$. PBP-6 seems to be related to PBP-5 but its function is unknown. D-Alanine carboxypeptidases IA and IB, that is PBP-5 and 4, were thought not to be important in the synthesis of peptidoglycan ${ }^{6,7)}$, but recently it was found that dacA mutant cells deficient in D-alanine carboxypeptidase IA are more sensitive to penicillins, cephalosporins and, under certain conditions, cephamycins than $\operatorname{dac} A^{+}$cells ${ }^{10}$.

PBP-4, which is identical with D-alanine carboxypeptidase IB, may also play some role when the cells are deficient in PBP-1Bs ${ }^{51}$. Nothing is yet known about the functions of PBP-7 and 8.

The facts that cefoxitin has high affinities to PBP-1A, 1 Bs and 3 may explain its strong bactericidal potency, because these PBPs are essential in elongation of cell wall peptidoglycan and in septum formation. It is unknown whether the high affinities to PBP-4 and 5 (and 6) contribute to the antibacterial activity of the antibiotic, because these PBPs do not seem to be very important for cell proliferation under normal conditions. The recent finding ${ }^{10)}$ that a defect in PBP-5 results in super-sensitivity of the cells to several antibiotics suggests, that binding of an antibiotic to this PBP has a secondary effect of increasing the sensitivity of the cells to the antibiotic.

Table 1 shows the affinities of cefoxitin to each E. coli PBP, calculated as the concentration ratios of

Table 1. Competition of antibiotics with $\left[{ }^{14} \mathrm{C}\right]$ benzylpenicillin for binding to PBPs in cytoplasmic membranes of $E$. coli in vitro.

\begin{tabular}{l|c|c}
\hline \multirow{2}{*}{ PBP } & \multicolumn{2}{|c}{ Concentration ${ }^{\mathrm{a}}$ of } \\
\cline { 2 - 3 } & Cefoxitin & Benzylpenicillin \\
\hline 1A & 0.3 & 0.8 \\
$1 \mathrm{Bs}$ & 0.8 & 0.8 \\
2 & $>25$ & 0.8 \\
3 & 1.5 & 0.9 \\
4 & 0.6 & 0.8 \\
$4^{\prime}$ & $>25$ & 1 \\
5 & 0.3 & $2.5^{\mathrm{b}}$ \\
6 & 1.1 & $2.2^{\mathrm{b}}$ \\
$7 / 8^{\mathrm{c}}$ & $<0.2^{\mathrm{a}}$ & 0.9 \\
\hline
\end{tabular}

a Concentration as a molar ratio to $\left[{ }^{14} \mathrm{C}\right]$ benzylpenicillin required for $50 \%$ inhibition of binding of $\left[{ }^{14} \mathrm{C}\right]$ benzylpenicillin. The table is compounded from data obtained in several independent experiments.

b Higher concentrations than 1 indicate either that the protein was not saturated with $\left[{ }^{14} \mathrm{C}\right]$ benzylpenicillin or that the protein released or degraded this compound.

c PBP-7 and 8 were measured together.

d The remaining radioactivity of $\left[{ }^{14} \mathrm{C}\right]$ benzylpenicillin in the presence of 0.2 times (molar ratio) the amount of unlabeled cefoxitin was $25 \%$. cefoxitin to $\left[{ }^{14} \mathrm{C}\right]$ benzylpenicillin needed for $50 \%$ competition, i.e., $50 \%$ inhibition of binding of $\left[{ }^{14} \mathrm{C}\right]$ benzylpenicillin. Table 1 also shows the concentration ratios for $50 \%$ competition of unlabeled benzylpenicillin with $\left[{ }^{14} \mathrm{C}\right]$ benzylpenicillin. Theoretically, the values for homologous competition should be 1 for each PBP, but in practice they vary from 0.8 to 2.5 for some unknown reason.

Of the enzyme reactions with which the PBPs can be correlated, only 4 reactions can now be measured: the D-alanine carboxypeptidase IA reaction, for which $\mathrm{PBP}-5$ is responsible, the Dalanine carboxypeptidase IB reaction, for which PBP-4 is responsible, formation of cross-linked peptidoglycan and concomitant release of $\mathrm{D}$ alanine. PBP-1Bs seems to be responsible for the last 2 reactions, but it is possible that the release of D-alanine concomitant with the crosslinking reaction is due to another enzyme(s). The enzymatic reactions due to PBP-1A, 2, 3, 6, 7 and 8 have not yet been identified. Table 2 shows the concentrations of cefoxitin causing $50 \%$ inhibition of these 4 reactions. Cefoxitin inhibited all 4 reactions at much lower con-

centrations than benzylpenicillin. In these 4 reactions the inhibitory potencies of the antibiotic correlate approximately with its affinities to the corresponding PBPs. 
Table 2. Concentrations of antibiotics required for $50 \%$ inhibition of the activities of D-alanine carboxypeptidases IA and IB, the peptidoglycan cross-linking reaction and concomitant release of D-alanine

\begin{tabular}{c|l|c|c|c}
\hline \multirow{2}{*}{ Exp. } & \multicolumn{1}{|c|}{ Reaction } & $\begin{array}{c}\text { PBP responsible } \\
\text { for the } \\
\text { reaction }\end{array}$ & \multicolumn{2}{|c}{ Concentration $(\mu \mathrm{g} / \mathrm{ml})$ of } \\
\cline { 4 - 5 } & & 5 & 0.02 & 1 \\
\hline 1 & D-Alanine carboxypeptidase IA & 4 & 0.005 & 0.01 \\
3 & D-Alanine carboxypeptidase IB & $1 \mathrm{Bs}$ & 0.5 & 3 \\
4 & $\begin{array}{l}\text { Cross-linking of peptidoglycan in vitro } \\
\text { D-Alanine release concomitant with cross- }\end{array}$ & (1Bs?) & 0.6 & 3 \\
\hline
\end{tabular}

Reaction mixtures contained in a final volume of $33 \mu \mathrm{l}$ : exps. 1 and 2, $2 \mu$ mol Tris- $\mathrm{HCl}$ buffer, $\mathrm{pH} 8.6$, $1 \mu \mathrm{mol} \mathrm{MgCl}, 0.44$ nmol UDP-MurNAc-L-Ala-D-Glu-m-A $\mathrm{Am}_{2}$-D-[14C]Ala-D-[ $\left.{ }^{14} \mathrm{C}\right] \mathrm{Ala}, 50$ nmol 2-mercaptoethanol, $0.1 \%$ (wt/vol, final) Triton X-100 and $100 \mu \mathrm{g}$ enzyme (as protein); exp. 3, $2 \mu \mathrm{mol}$ Tris- $\mathrm{HCl}$ buffer, pH 8.6, $1 \mu \mathrm{mol} \mathrm{MgCl}_{2}, 0.35$ nmol UDP-MurNAc-L-Ala-D-Glu-m-[14C]A ${ }_{2}$ pm-D-Ala-D-Ala, 10 nmol UDPGlcNAc, $50 \mathrm{nmol}$ 2-mercaptoethanol and $100 \mu \mathrm{g}$ enzyme (as protein); exp. 4, as for exps. 1 and 2, except that $10 \mathrm{nmol}$ UDP-GlcNAc was present and $0.1 \%$ (wt/vol, final) Triton X-100 was omitted.

\section{References}

1) Karady, S.; S. H. Pines, L. M. Weinstock, F. E. Roberts, G. S. Brenner, A. M. Hoinowski, T. Y. Cheng \& M. Sletzinger: Semisynthetic cephalosporins via a novel acyl exchange reaction. J. Am. Chem. Soc. 94: $1410 \sim 1411,1972$

2) Spratt, B. G.: Properties of the penicillin-binding proteins of Escherichia coli K12. Eur. J. Biochem. 72 : $341 \sim 352,1977$

3) Ohya, S.; M. Yamazaki, S. Sugawara, S. Tamaki \& M. Matsuhashi: Studies on a new cephamycin antibiotic, CS-1170: Binding affinity to penicillin-binding proteins and inhibition of peptidoglycan-crosslinking reactions in E. coli. Antimicr. Agents \& Chemoth. 14: 780 785, 1978

4) Noguchi, H.; M. Matsuhashi, M. Takaoka \& S. Mitsuhashi: Studies on a new antipseudomonal penicillin, PC-904: Affinity to penicillin-binding proteins and inhibition of the enzyme crosslinking peptidoglycan. Antimicr. Agents \& Chemoth. 14:617 624, 1978

5) TAmaki, S.; S. Nakajima \& M. Matsuhashi: Thermosensitive mutation in Escherichia coli simultaneously causing defects in penicillin-binding protein-1Bs and in enzyme activity for peptidoglycan synthesis in vitro. Proc. Natl. Acad. Sci., U.S.A. 74: 5472 5476, 1977

6) Matsuhashi, M.; Y. Takagaki, I. N. Maruyama, S. Tamaki, Y. Nishimura, H. Suzuki, U. Ogino \& Y. Hirota: Mutants of Escherichia coli lacking in highly penicillin-sensitive D-alanine carboxypeptidase activity. Proc. Natl. Acad. Sci., U.S.A. 74: 2976 2979, 1977

7) Matsuhashi, M.; I. N. Maruyama, Y. Takagaki, S. Tamaki, Y. Nishimura \& Y. Hirota: Isolation of a mutant of Escherichia coli lacking in the activity of a penicillin-sensitive D-alanine carboxypeptidase IA. Proc. Natl. Acad. Sci., U.S.A. 75: 2631 2635, 1978

8) Spratt, B. G.: Distinct penicillin binding proteins involved in the division, elongation, and shape of Escherichia coli K12. Proc. Natl. Acad. Sci., U.S.A 72: 2999 3003, 1975

9) Iwaya, M. \& J. L. Strominger: Simultaneous deletion of D-alanine carboxypeptidase IB-C and penicillin-binding component IV in a mutant of Escherichia coli K-12. Proc. Natl. Acad. Sci., U.S.A. 74: 2980 2984, 1977

10) Tamaki, S.; J. Nakagawa, I. N. Maruyama \& M. Matsuhashi: Supersensitivity to $\beta$-lactam antibiotics in Escherichia coli caused by D-alanine carboxypeptidase IA mutation. Agr. Biol. Chem. (Tokyo) 42: $2147 \sim 2150,1978$ 